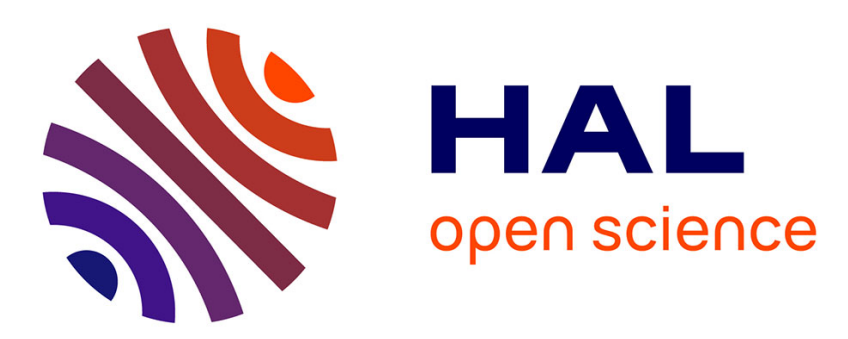

\title{
High-Frequency Model of the Coupled Inductors Used in EMI Filters
}

Jean-Luc Kotny, Xavier Margueron, Nadir Idir

\section{To cite this version:}

Jean-Luc Kotny, Xavier Margueron, Nadir Idir. High-Frequency Model of the Coupled Inductors Used in EMI Filters. IEEE Transactions on Power Electronics, 2012, 27 (6), pp.2805 - 2812. 10.1109/TPEL.2011.2175452 . hal-01886795

\section{HAL Id: hal-01886795 \\ https://hal.science/hal-01886795}

Submitted on 3 Oct 2018

HAL is a multi-disciplinary open access archive for the deposit and dissemination of scientific research documents, whether they are published or not. The documents may come from teaching and research institutions in France or abroad, or from public or private research centers.
L'archive ouverte pluridisciplinaire HAL, est destinée au dépôt et à la diffusion de documents scientifiques de niveau recherche, publiés ou non, émanant des établissements d'enseignement et de recherche français ou étrangers, des laboratoires publics ou privés. 


\title{
High Frequency Model of the coupled inductors used in EMI Filters
}

\author{
Jean-Luc Kotny ${ }^{1,2}$, Xavier Margueron ${ }^{1,3}$, Member, IEEE, and Nadir Idir $^{1,2}$, Member, IEEE \\ ${ }^{1}$ Univ Lille Nord de France, F-59000 Lille, France \\ ${ }^{2}$ USTL, L2EP, F-59650 Villeneuve d'Ascq, France \\ ${ }^{3}$ ECLille, L2EP, F-59650 Villeneuve d'Ascq, France
}

Dr Jean-Luc Kotny

Université de Lille 1

Laboratoire L2EP - Bât. P2 - Cité Scientifique

F-59655 Villeneuve d'Ascq Cedex -FRANCE

Tel. 33 (0)320.43.48.62 - Fax. 33 (0)320.43.69.67

Email: Jean-Luc.Kotny@univ-lille1.fr

Dr Xavier Margueron

Ecole Centrale de Lille - L2EP

Cité Scientifique

F-59651 Villeneuve d'Ascq Cedex -FRANCE

Tel. 33 (0)320.33.53.88 - Fax. 33 (0)320.33.54.54

Email: Xavier.Margueron@ec-lille.fr

Prof Nadir Idir

Université de Lille 1

Laboratoire L2EP - Bât. P2 - Cité Scientifique

F-59655 Villeneuve d'Ascq Cedex -FRANCE

Tel. 33 (0)320.33.77.90 - Fax. 33 (0)320.43.69.67

Email: Nadir.Idir@univ-lille1.fr

Paper has been presented at conference :

- $\quad$ IEEE Energy Conversion Congress and Exposition - ECCE’09.

Abstract - This paper deals with a high frequency modeling method of the coupled inductors used in EMI filters. These filters are intended to reduce conducted emissions generated by power static converters towards the power grid. To model the EMI filters, it is necessary to identify the various parameters of the passive elements: inductors and capacitors. Because of their major impact on filter efficiency, these elements must be identified with accuracy. In this study, high frequency model of common mode coupled inductors is proposed. The identification of the model parameters is based on the experimental approach. Simulation results of the proposed model are compared to the experimental data obtained using the specific experimental setup. These results made it possible to validate the EMI filter model and its robustness in a frequency range varying from $9 \mathrm{kHz}$ to $30 \mathrm{MHz}$. The proposed high frequency inductor models will be very helpful for design and optimization of EMI filters, since the high frequency behavior of the filter mainly depends on magnetic materials used and on the geometrical characteristics of winding. 


\section{INTRODUCTION}

Nowadays, the increase of power converter number is very problematic for electromagnetic compatibility (EMC). Indeed, each power static converter generates a lot of high frequency (HF) interferences toward the power network which becomes more and more polluted [1]. The main solution to reduce these conducted emissions is based on the utilization of EMI filters [2]-[3]. It can also be combined with other solutions like the slowing down the $\mathrm{dv} / \mathrm{dt}$ and $\mathrm{di} / \mathrm{dt}$ during the transitions of the power semiconductor components and/or by acting on the converter controls [4]-[5].

The EMI filters are made of coupled inductors combined with capacitors; the choice of the topology depends on network and load impedances. A typical differential mode (DM) and common mode (CM) filter used for power converter is shown in Fig.1.

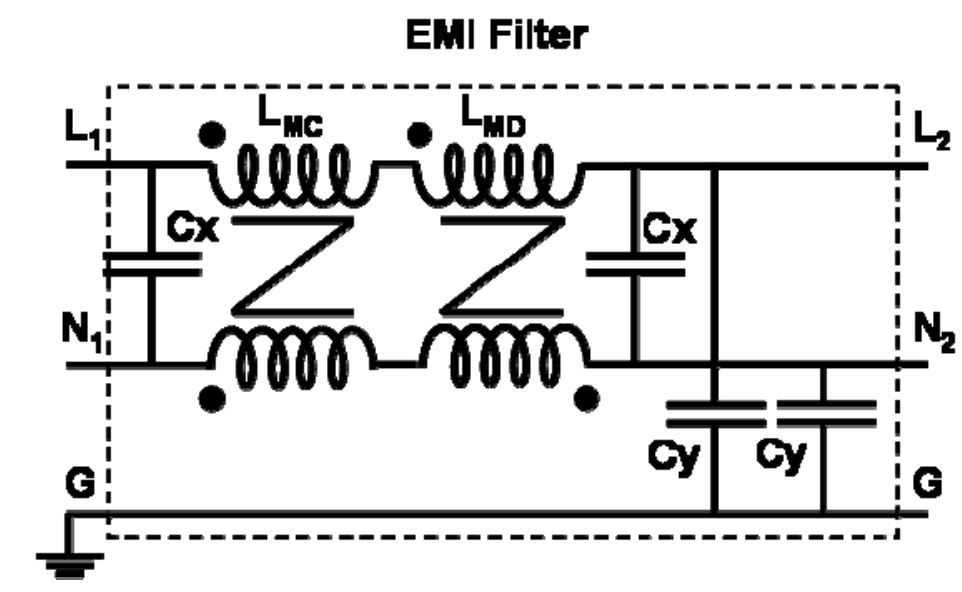

Fig. 1. Typical EMI Filter topology

It is well-known that magnetic components have a strong impact on filter efficiency [6]-[7]. They are typically made with copper wiring on high permeability ring ferrite. These chokes are traditionally designed by a "cut and try" process, which is very expensive and time consuming because of the high number of prototypes which are needed. Wires specifications and their placement, PCB characteristics, or magnetic core performances introduce parasite effects that can reduce drastically the filter's efficiency [8]-[9].

The stray elements of the passive components, such as equivalent series inductor (ESL) of capacitors and equivalent parallel capacitor (EPC) of inductors, degrade the performances of the EMI filters. While for a lot of cases, their influence is less important than the couplings among components and layouts [10].

In order to design and optimize the performance of the filter by simulation, a high frequency model, including parasitic elements, must be used. These elements must be identified with a good accuracy [11]. In this paper, a high frequency modelling method of the coupled inductors of EMI filter is presented. The new equivalent circuit is detailed and its characterisation process is described. The obtained model is tested with different magnetic material and gives good results on a large frequency range from $1 \mathrm{kHz}$ to $30 \mathrm{MHz}$. In order to validate the proposed model and to test its reliability, a common mode inductors and 
capacitors are used to realise an EMI filters. The simulation results using the high frequency model of the filter are validated by experimental measurements. In the following section, high frequency modelling method of the coupled inductors is detailed.

\section{HIGH FREQUENCY MODEL OF COUPLED INDUCTORS}

In this study, a prototype of the coupling inductors has been realized with EPCOS ferrite material N30 [12]. The core shape is a ring R58.3/40.8/17.6 and each winding is made of 15 turns of copper (diameter 1.5mm). At first, we will propose an equivalent circuit model of the coupled inductors. Then, we propose an experimental method of characterization of the passive component which will enable to identify the model parameters.

\section{A. Equivalent Circuit of the coupled inductors}

Coupled inductors used in EMI filters are a specific case of traditional n-windings magnetic components [13]-[14] because they are made with two identical windings around a magnetic core (Fig. 2a). The objective is to have a model of coupled inductors based on equivalent electrical circuit that enable to describe the various physical phenomena (magnetic and electrostatic) which appear in high frequency. In order to have a more precise model, a symmetrical equivalent circuit of these inductors, is used (Fig. 2b). The proposed model is a lumped model; it uses only R, L, and C elements to describe its behaviour in a large frequency range. Half of the equivalent circuit is made of three impedances $Z_{1}$ (x2) and $Z_{2}$, an ideally coupled inductors and four different capacitors $\mathrm{C}_{\mathrm{S}}, \mathrm{C}_{\mathrm{e}}, \mathrm{C}_{\mathrm{P}}, \mathrm{C}_{\mathrm{C}}$.

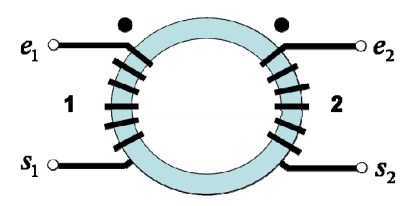

(a): Common mode inductors

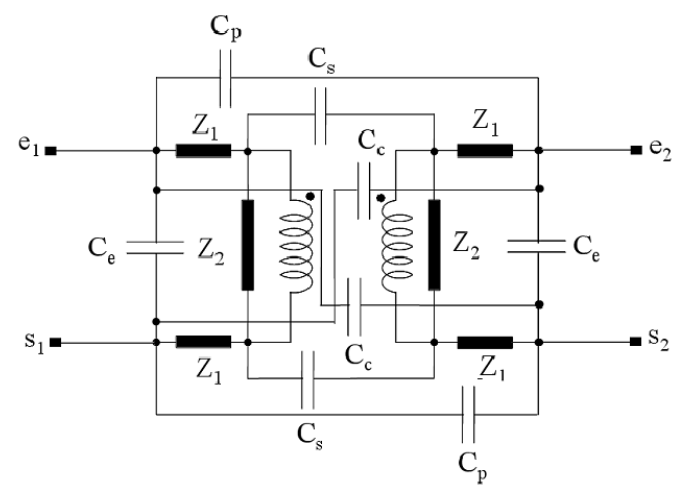

(b): High frequency equivalent circuit

Fig. 2. High frequency model of the coupled inductors 
It is known that for a 2-windings transformer model, with a strong magnetic coupling, only three capacitors are necessary to describe its electrostatic behaviour [14]. In the case of the coupled inductors and in order to have a symmetric model (for each winding), a supplementary capacitor $\mathrm{C}_{\mathrm{S}}$ has been added to the circuit as shown in Fig. $2 \mathrm{~b}$.

\section{B. Parameters identification method}

In order to determine the parameters of the common mode inductors model (Fig 2b), impedance measurements realized in different test configurations are necessary. An impedance analyzer (Agilent 4294A) is then used and it enables to obtain impedance measurements (modulus and phase) on a large frequency range from $1 \mathrm{kHz}$ to $100 \mathrm{MHz}$ [15].

To identify the various impedances of magnetic component, different test configurations can be carried out [16]. Due to the geometrical symmetry of coupled inductors and using the equivalent circuit presented in the Fig. 2b, only five well-chosen measurements, as shown in Fig. 3, should be sufficient for determine all the magnetic and electrostatic parts of the model.

In order to determine all the parameters of the coupled inductors model, different kind of impedance are necessary. For example, subtracting flux or additional flux measurements are realized and only one open circuit measurement is used for the magnetizing inductance identification. Figure 3 describes the main five measurement configurations $\left(T_{0}\right.$ until $\left.T_{4}\right)$ that are chosen to identify the equivalent circuit elements of the coupled inductors.

In the determination process of the model parameters, the first configuration $T_{0}$ is used to identify the leakage impedance $Z_{1}$.

Then, $T_{0}, T_{1}, T_{2}$ and $T_{3}$ are combined to calculate the four capacitances and finally $T_{4}$ enables to identify the magnetizing part of the component. The Table I sum up the various measurement configurations which allow to identify the model parameters. The five impedances measured on the prototype using the impedance analyzer are shown in Figures 4 and 5.

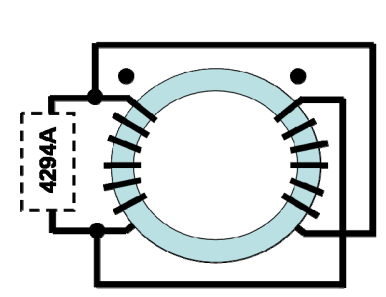

(a): Parallel windings Subtracting flux $\left(T_{0}\right)$

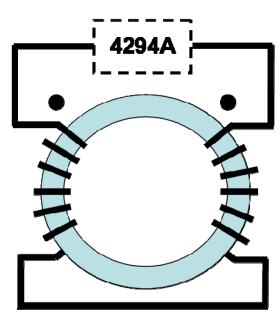

(b): Series windings Subtracting flux $\left(T_{1}\right)$

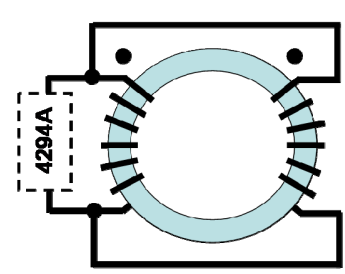

(c): Parallel windings Additional flux $\left(T_{2}\right)$

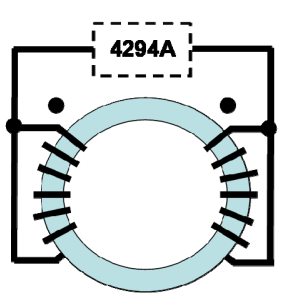

(d): Between e1 and e2 with two short circuits $\left(T_{3}\right)$

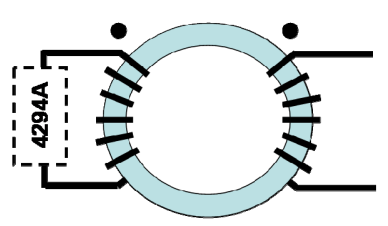

(e): Open circuit $\left(T_{4}\right)$

Fig. 3. Impedance measurement configurations

TABLE I

MODEL PARAMETERS IDENTIFICATION

\begin{tabular}{|c|c|}
\hline moded perarnters & 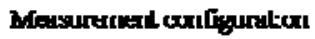 \\
\hline Cepacibanocs (G, G, G,,$\left.C_{2}\right)$ & $\mathbf{T}_{\mathbf{n}}, \mathbf{T}_{\mathbf{L}}, \mathbf{T}_{\mathbf{2}}, \mathbf{T}_{\mathbf{3}}$ \\
\hline $\mathbf{Z}_{\mathbf{A}}\left(\mathbf{R}_{\mathbf{L}}, \mathbf{L}\right)$ & $\mathbf{T}_{\mathbf{0}}, \mathbf{T}_{\mathbf{l}}$ \\
\hline$Z_{2}\left(G_{2}, L_{1}, C_{2}, R_{2}^{\prime}, L_{2}^{\prime}, C_{2}^{\prime}, R_{2}\right)$ & $\mathbf{T}_{\mathbf{2}}, \mathbf{T}_{\mathbf{4}}$ \\
\hline
\end{tabular}




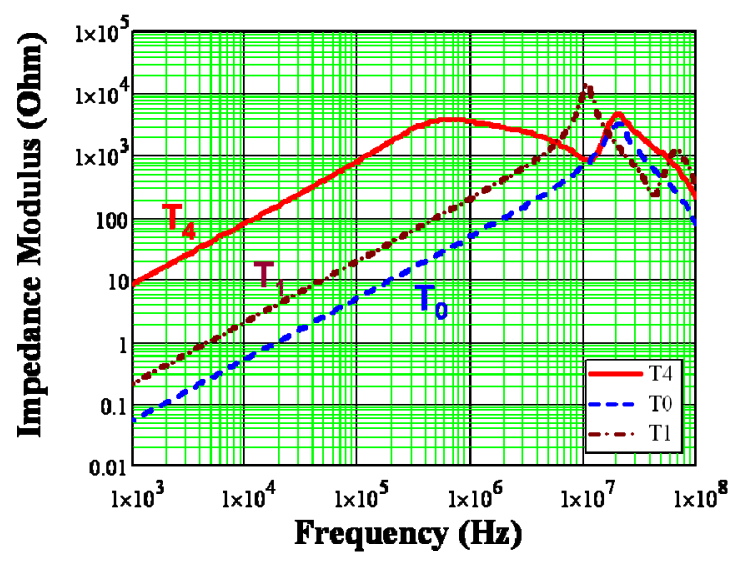

Fig. 4. Impedance (modulus) measurement configurations $\left(T_{0}, T_{1}, T_{4}\right)$

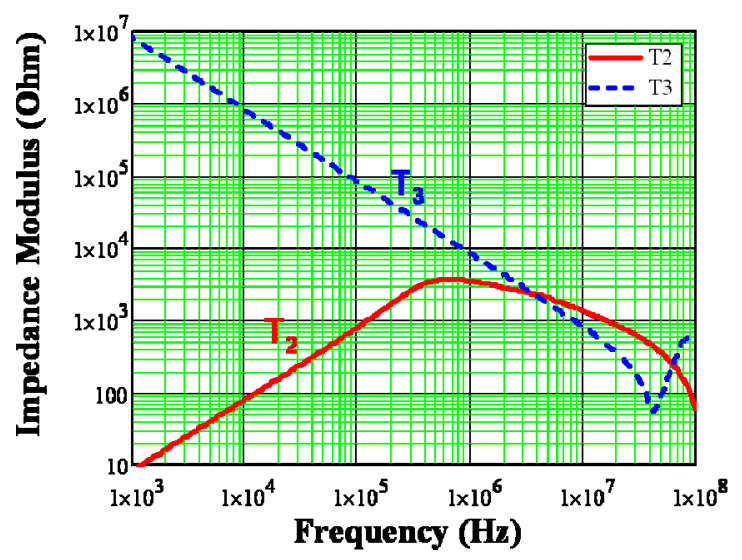

Fig. 5. Impedance (modulus) measurement configurations $\left(T_{2}, T_{3}\right)$

The impedance measured in configuration $T_{3}$ is quite different from the others because it corresponds to a capacitive behaviour from $1 \mathrm{KHz}$ to $30 \mathrm{MHz}$. Indeed, this impedance is measured between both windings short circuited so the measurement is equivalent to a capacitance.

\section{DETERMINATION OF THE MODEl PARAMETERS}

All impedances are modeled by one or more combination of RLC circuit. The aim of this section is to propose equivalent circuits which allow to model the frequency variation of leakage impedance $\left(Z_{1}\right)$, magnetizing impedance $\left(Z_{2}\right)$ and the 4 capacitors $\left(C_{c}, C_{e}, C_{p}\right.$ and $\left.C_{s}\right)$ of the coupled inductors shown in Fig. 2 b.

\section{A. Leakage Impedance}

The leakage impedance parameters are obtained from the measurement configuration $T_{0}$ because windings are connected in a subtracting flux topology (cancellation of magnetizing flux). The impedance obtained from $T_{0}$ corresponds to parallel RLC impedance which the equivalent circuit is shown in Fig. 6. The inductance $L_{1}$ is identified in frequency band (between $1 \mathrm{kHz}$ 
and $3.7 \mathrm{MHz}$ ) when the impedance measured in this configuration increases (and phase equal to $90^{\circ}$ ). The inductance variation (with frequency) is due to eddy current effects in the copper wires. Until the resonance frequency, the error between the model and the measurement is still lower than 5\%. The obtained model is quite simple but can be improved using ladder RL circuits in order to model correctly the eddy current effects [14]. The value of the resistance $R_{l}$ is measured at the resonance frequency $\left(f_{r}=19.9 \mathrm{MHz}\right)$ of the impedance obtained from $T_{0}$ as shown in Fig. 4. The capacitance of the equivalent circuit of the coupled inductor in configuration $T_{0}$ is given by $C_{0}=2\left(C_{e}+C p\right)$.

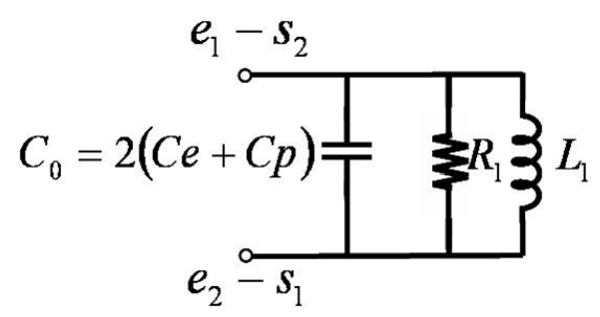

Fig. 6. Equivalent circuit of the measurement configuration $\left(T_{0}\right)$

From the curve $\left(T_{0}\right)$ shown in Fig. 4 , the capacitance $C_{0}$ is computed from the resonance frequency $\left(f_{r}=19.9 \mathrm{MHz}\right)$ using equation (1). This capacitance corresponds to the combination of both capacitances $C_{e}$ and $C_{p}$. The table II sums up these leakage parameter values.

$$
C_{0}=\frac{1}{\left(2 \pi \cdot f_{r}\right)^{2} \cdot L_{1}}
$$

TABLE II

LEAKAGE PARAMETERS

\begin{tabular}{|c|c|c|c|}
\hline Parameters & $R_{1}$ & $L_{t}$ & $c_{1}$ \\
\hline Values & 33000 & $8.2 \mu \mathrm{H}$ & $7.8 \mathrm{pF}$ \\
\hline
\end{tabular}

\section{B. Parasitic Capacitances}

The capacitance value $\mathrm{C}_{0}$ is identified from the leakage impedance measured in configuration $T_{0}$. However, it remains three other capacities to calculate. With three more equations, the system can be solved. These equations are given by measurements carried out in configurations $T_{1}, T_{2}$ and $T_{3}$. Their equivalent circuits are presented in Fig. 7. 


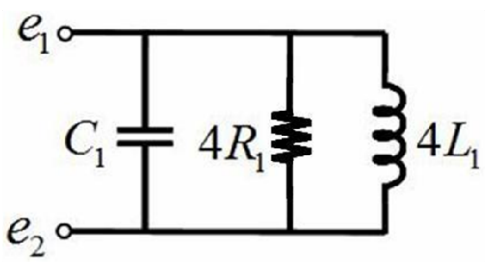

(a): configuration $\left(T_{1}\right)$

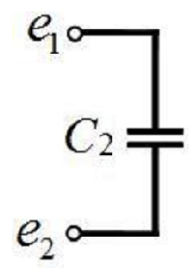

$e_{2}-S_{2}$

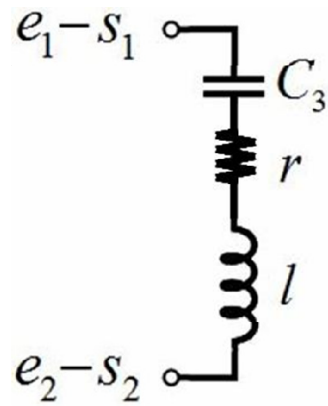

(c): configuration $\left(T_{3}\right)$

Fig. 7. Equivalent circuit of three measurement configurations

The impedance measured in configuration $T_{1}$ is quite similar to $T_{0}$. Thus, the model used is also a parallel RLC circuit (Fig.7a). The measured values of $\mathrm{R}$ and $\mathrm{L}$ are four times higher than the leakage parameters. The capacitance value $C_{1}$ is also determined from the resonance frequency. The value of this capacitance is given by the following relation:

$$
C_{1}=C_{S}+C_{p}+\frac{C_{C}+C_{e}}{2}=6.8 p F
$$

The equivalent circuit of the impedance measured in configuration $T_{2}$ cannot use only one RLC series circuit. Indeed, one will show, in the next section, that the magnetizing impedance will require three RLC circuits to describe its high frequency behaviour. Because the focus is on the electrostatic part of the impedance, for frequency upper than $50 \mathrm{MHz}$, a tangent of the impedance curve is plotted. The obtained equivalent capacitance is equal to:

$$
C_{2}=2\left(C_{e}+C_{C}\right)=8 p F
$$

The last needed equation is given by impedance measured in the configuration $T_{3}$. Its equivalent representation is a RLC series circuit shown in the Fig.7c. The capacitance is easily evaluated between $1 \mathrm{kHz}$ and $4 \mathrm{MHz}$ using the imaginary part of the measured impedance. The equivalent capacitance is equal to:

$$
C_{3}=2\left(C_{P}+C_{C}+C_{S}\right)=19.2 p F
$$

Finally, these measurements lead to a 4-unknown equations system (5) that can be easily solved and the obtained results are given in (6)

$$
\left\{\begin{array}{c}
2 C e+2 C p=C_{0} \\
\frac{C c}{2}+\frac{C e}{2}+C p+C s=C_{1} \\
2 C e+2 C c=C_{2} \\
2 C c+2 C p+2 C s=C_{3}
\end{array}\right.
$$




$$
\left\{\begin{array}{c}
C c=-C_{1}+\frac{C_{2}}{4}+\frac{C_{3}}{2} \\
C e=C_{1}+\frac{C_{2}}{4}-\frac{C_{3}}{2} \\
C p=\frac{C_{0}}{2}-C_{1}-\frac{C_{2}}{4}+\frac{C_{3}}{2} \\
C s=-\frac{C_{0}}{2}+2 C_{1}-\frac{C_{3}}{2}
\end{array}\right.
$$

The table III sums up the obtained values for the four capacitances.

TABLE III

CAPACITOR VALUES

\begin{tabular}{|c|c|c|c|}
\hline $\mathbf{C}_{\mathbf{c}}$ & $\mathbf{C .}_{\mathbf{6}}$ & $\mathbf{C}_{\mathbf{p}}$ & $\mathbf{C}_{\mathbf{3}}$ \\
\hline $4.8 \mathrm{pF}$ & $-0.8 \mathrm{pF}$ & $4.7 \mathrm{pF}$ & $0.1 \mathrm{p} Z$ \\
\hline
\end{tabular}

One can note that the value of the capacity $\mathrm{C}_{\mathrm{e}}$ is negative. This can be justified by the simplicity of the proposed behaviour model of the impedances and also to the measurement errors related to the accuracy of the impedance analyzer (measurement equipment).

\section{Magnetizing Impedance}

The impedance measured in configuration $T_{4}$ enables to characterize the magnetizing part $Z_{2}$ of the component. Thus, such impedance, shown in Fig. 8, cannot be described by only one RLC circuit. Three different circuits have to be used in order to describe the three areas.

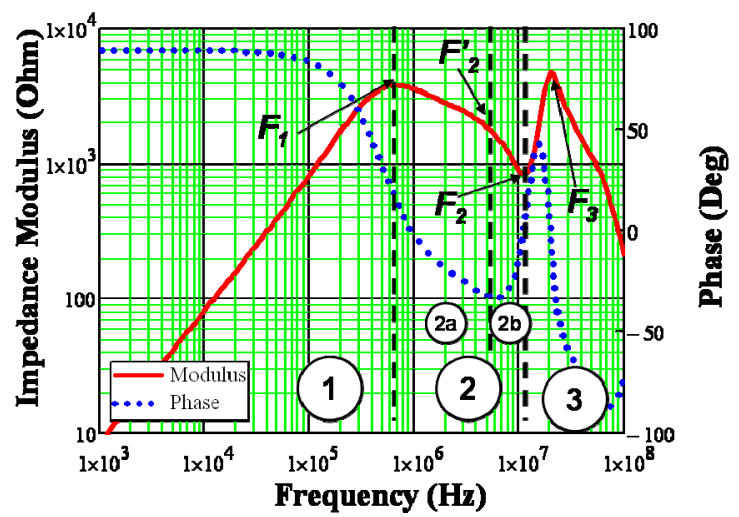

Fig. 8. Impedance modulus in open circuit (configuration $\left(T_{4}\right)$ )

- The first area, from low frequency to $F_{1}=670 \mathrm{kHz}$, corresponds to the proper inductance traditionally calculated using the following relation:

$$
L=N^{2} \cdot A_{L}
$$

With:

$\mathrm{N}$ : winding turns, 
$\mathrm{A}_{\mathrm{L}}$ : inductance factor.

The inductance factor of the ferrite material $\mathrm{N} 30$, used to realized a prototype of the coupling inductors, is equal to $\mathrm{A}_{\mathrm{L}}=5400 \pm$ $20 \%$. Thus, it's well known that the characteristics of magnetic materials used in the design of the EMI filters depend on the levels and frequencies ranges of the conducted disturbances to be attenuated.

- The second area, from $F_{1}$ to $F_{2}=11 \mathrm{MHz}$, corresponds to high frequency effects of the magnetic material. This frequency band is divided into two parts $2 \mathrm{a}$ and $2 \mathrm{~b}$. At the frequency $\mathrm{F}_{2}{ }_{2}$, one can note a slope break of the impedance modulus, thus, the magnetic material effect is masked by an electrostatic effect.

- In the third area, a resonance appears which can be linked to the inductive leakage phenomena combined with electrostatic effects.

The magnetizing impedance evolution measured in configuration $T_{4}$ is shown in Fig. 8. The equivalent circuit at this impedance, which corresponds only to the area 1 and 2, is shown Fig. 9a. In this frequency band (area 1 and 2), the influence of the leakage inductances and the parasitic capacitances is negligible.

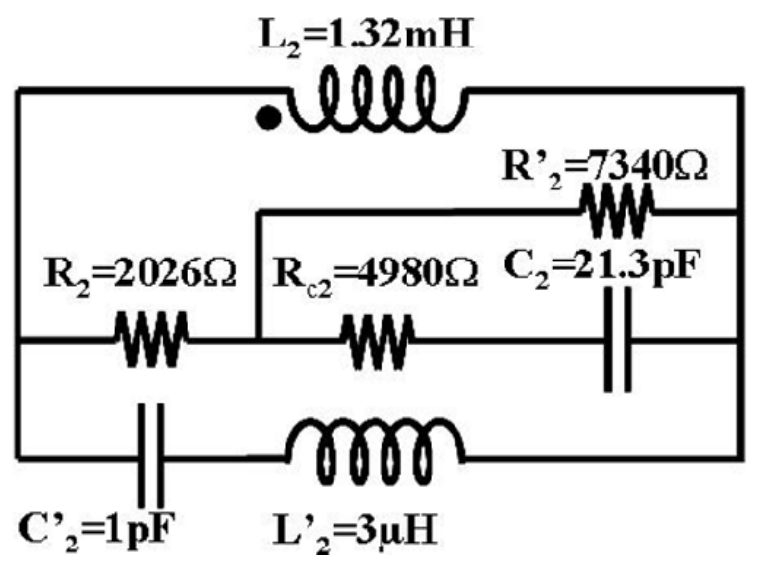

(a) The equivalent circuit of the magnetizing impedance 


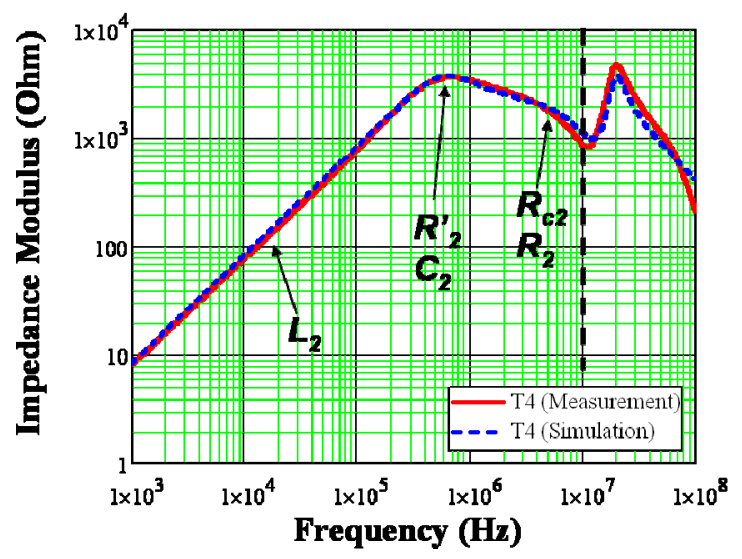

(b) Comparison of the impedance modulus in configuration (T4)

Fig. 9. Modelling of the magnetizing impedance

The value of $L_{2}$ is calculated using the imaginary part of the impedance $\left(L_{2}=Z_{2} \sin \theta / \omega\right)$ in the frequency band between 1 $\mathrm{KHz}$ and $370 \mathrm{kHz}$ as shown in the Fig. 8 (or using relation (7)). The obtained value of this inductance is equal to $L_{2}=1.32 \mathrm{mH}$.

The elements $R_{2}^{\prime}$ and $C_{2}$ are obtained from the first resonance frequency $F_{1}=670 \mathrm{KHz}$ (Fig. 8). The resistance value is equal to $R_{2}^{\prime}=7340 \Omega$. The capacitance $C_{2}$ is calculated with the following relation:

$$
C_{2}=\frac{1}{2 \cdot L_{2} \cdot\left(2 \pi \cdot F_{1}\right)^{2}}=21.4 p F
$$

The elements $R_{2}$ and $R_{C 2}$ fix the impedance slope between the frequencies $F_{1}$ and $F_{2}^{\prime}$ (area $2 \mathrm{a}$ ). The value of the resistance $R_{C 2}$ $=4980 \Omega$ is obtained from the impedance slope in this area. However, the resistance $R_{2}$ is calculated using the equivalent resistance at the frequency ${F^{\prime}}_{2}=3 \mathrm{MHz}$. Its value is equal to $R_{2}=2026 \Omega$.

The last equivalent circuit $L_{2}^{\prime}$ and $C_{2}^{\prime}$ is used to model the evolution of the impedance between $F_{2}^{\prime}$ and $F_{2}$ (area $2 \mathrm{~b}$ ). The values of these parameters are obtained by a fitting method using APLAC software. In order to show the influence of the various elements on the accuracy of the proposed model, we present in Fig. 10a the comparison between a simulation of the equivalent circuit of the magnetizing impedance without elements R2 and RC2. However, Fig. 10b show the simulation of the same circuit without elements L'2 and C'2. 


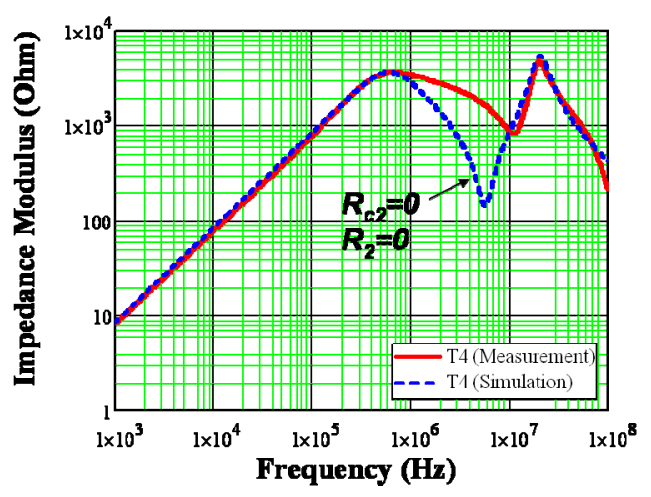

(a): Influence of $\mathrm{R}_{2}$ and $\mathrm{R}_{\mathrm{c} 2}$

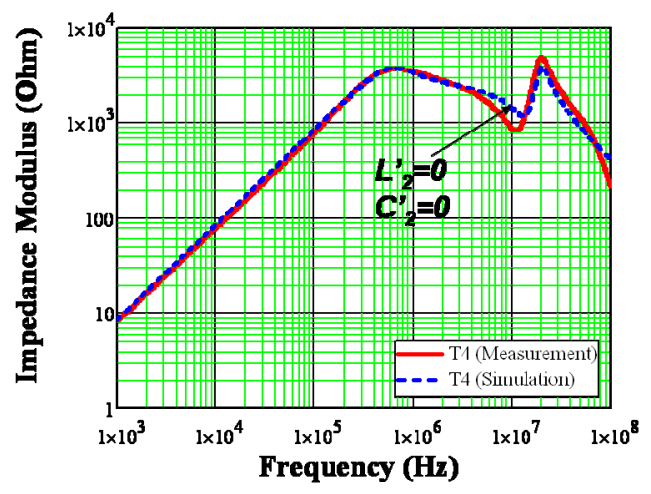

(b): Influence of $\mathrm{L}_{2}$ and $\mathrm{C}_{2}$

Fig. 10. Model of the magnetizing impedance

The comparison between simulation results and measurement data (Fig 9b) shows that the proposed equivalent circuit allows to model, with a good accuracy, the evolution of the magnetizing impedance $Z_{2}$. Figure 11 presents the final high frequency coupled inductors model. Its parameter values are listed in the Table IV. The obtained model uses only electrical equivalent circuits that enable to make simulations in frequency and time domains using simulator software such as SPICE. However, for time domain simulation, negative capacitances must be removed to positive one using inverse perfect couplers [14].

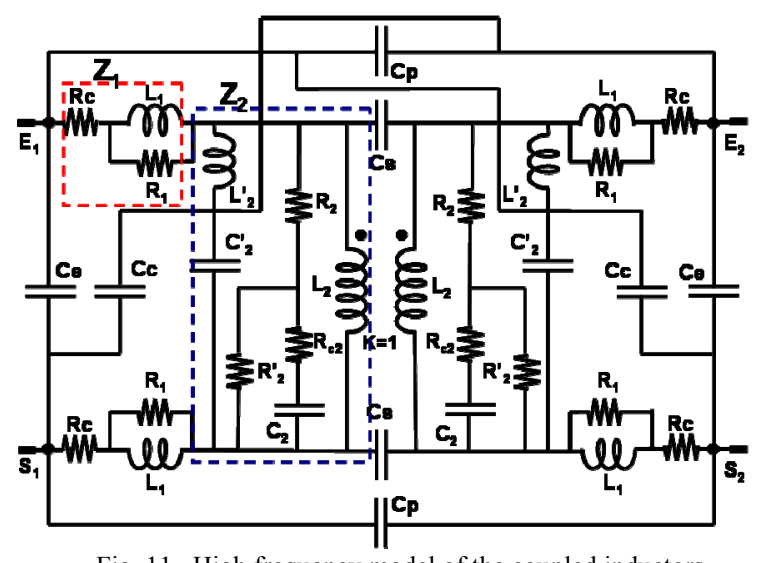

Fig. 11. High frequency model of the coupled inductors 
TABLE IV

EQUIVALENT CiRCUIT COMPONENT VALUES

\begin{tabular}{|c|c|c|c|}
\hline \multicolumn{2}{|c|}{ Hagntizing impedance } & $\begin{array}{l}\text { Lalkage } \\
\text { impederce }\end{array}$ & $\begin{array}{l}\text { Parasitic } \\
\text { Cepacitances }\end{array}$ \\
\hline $4-\mathrm{L} 32 \pi \mathrm{H}$ & $R_{n}-40000$ & $4-8.2 \pi$ & $C c=48 p F$ \\
\hline$R-73400$ & $G=3 \mu d t$ & $R_{4}=3300 \Omega$ & $C_{p}=-08 p p$ \\
\hline$C_{1}-21.3 p$ & $C_{1}-1 p r$ & $R z=48 m \Omega$ & $C_{p}=47 p F$ \\
\hline$R_{1}=20200$ & & & $a=0.1 p F$ \\
\hline
\end{tabular}

To complete the equivalent circuit, supplementary resistors $\mathrm{Rc}$ is added in series with impedance $\mathrm{Z}_{1}$ in order to model the low frequency winding resistance which measured with impedance analyzer. The validity of the obtained model will be discussed in the following section.

\section{MODEL VALIDATION}

To validate the proposed model, different configuration tests are considered. To study the robustness of the model, two other configurations: short circuit measurements $T_{5}$, open circuit $T_{6}$ as shown in Fig. 12 are used. The comparison between experimental data and simulation results, using SPICE software, is shown in Fig. 13. The obtained results show a good accuracy of the coupled inductors model up to $100 \mathrm{MHz}$. These results prove the validity and robustness of the proposed model. The next step consists to use the proposed model to study by simulation the design of the EMI filter which is made from common mode and differential mode filters.

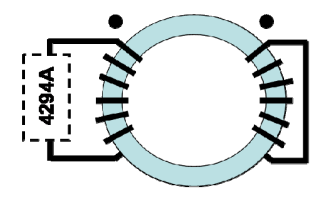

(a): Short-circuit of one winding $\left(T_{5}\right)$

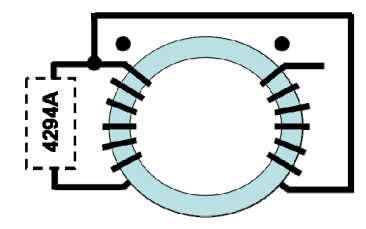

(b): open circuit with $\mathrm{e}_{1}-\mathrm{s}_{2}$ connected $\left(\mathrm{T}_{6}\right)$

Fig. 12. Impedance measurement configurations 


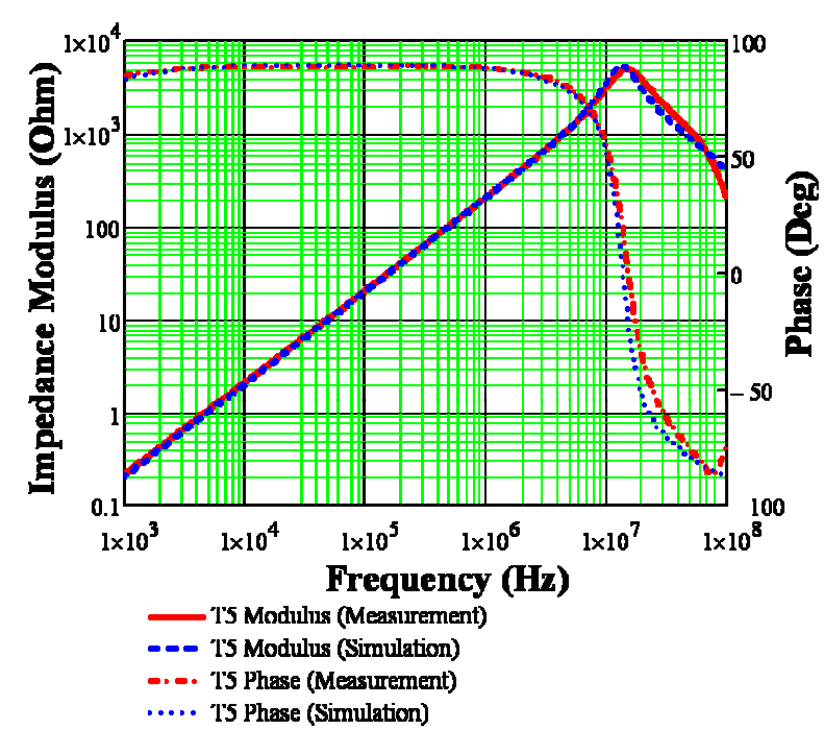

(a) : Configuration $T_{5}$

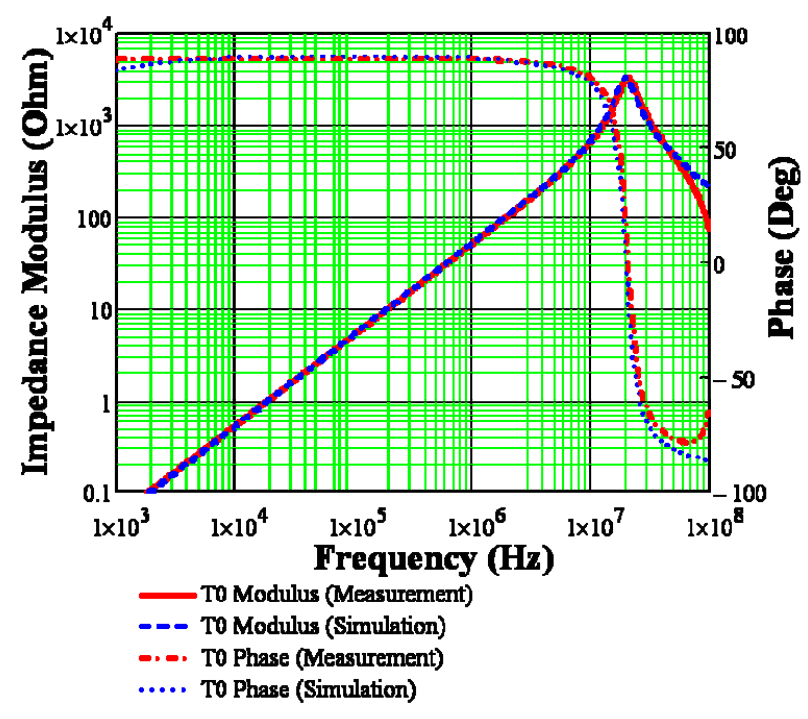

(c) : Configuration $T_{0}$
(d) : Configuration $T_{6}$

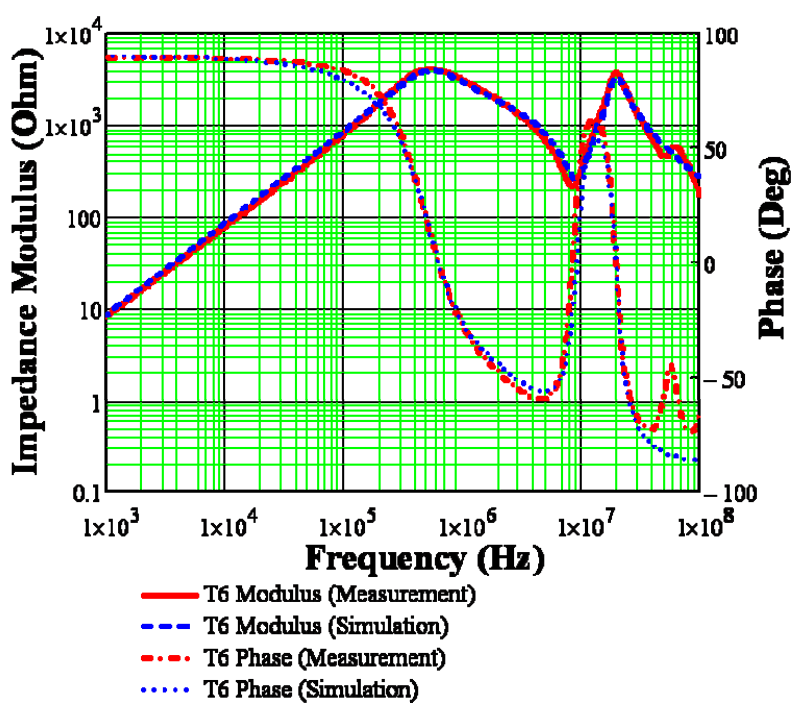

(d) : Configuration $T_{6}$

Fig. 13. Impedance evolution of the coupled inductors in four configuration tests (simulation and experimental)

\section{EMI FILTER APPLICATION}

The coupled inductors are associated with capacitors to achieve a complete EMI filter. Components are connected together on the PCB and placed inside a metallic box as shown in Fig. 14. Figure 15 shows the interior of the box which contains the common mode inductors and four capacitors $\mathrm{C}_{\mathrm{Y}}=4,7 \mathrm{nF}$. The two small boxes are the resistive dispatchers which used to divide the power injected in an equal way on the two inputs ports of the filter. For simulation, the capacitors " $\mathrm{C}_{\mathrm{Y}}$ " have been characterized using the impedance analyzer. The equivalent circuit used is a RLC series circuit: $C=4.9 n F, R=0.18 \Omega$, $R=6.4 n H$. The connection wires were also modeled [17]-[18]. 
Both common mode and differential mode filters have been tested according to experimental setup shown in Fig. 16. A spectrum analyzer (HP ESA L1500A) is used to characterize the common mode and the differential mode filters. In the differential mode configuration test, a high frequency balun (transformer) is added in order to obtain a balanced system. The Tracking RF generator power level (output side) is equal to $3 \mathrm{dBm}$ for the common mode characterization and $0 \mathrm{dBm}$ for the differential mode characterization. The filters are characterised with input/output impedances equal to $50 \Omega / 50 \Omega$.

The both configuration filter attenuations are calculated by simulation using the different components models (coupled inductors, capacitor $\mathrm{C}_{\mathrm{Y}}$, wires...). Figures 17 and 18 show comparison between measured and calculated attenuation for common mode and differential mode filters. For both configurations, these results show a low difference $(3 \mathrm{~dB})$ between measurement and simulation up to $30 \mathrm{MHz}$.

The filter attenuation depends mainly on the magnetic material and capacitors characteristics [19]-[21]. On the other hand, the maximum attenuation strongly depends on the filter realization ( $\mathrm{L}$ and $\mathrm{C}$ positioning, coaxial wire lengths, connections lengths...). In conclusion, filter efficiency mainly depends on its component characteristics and their relative positioning, so a particular care must be taken while realizing an EMI filter for reducing these parasitic effects.

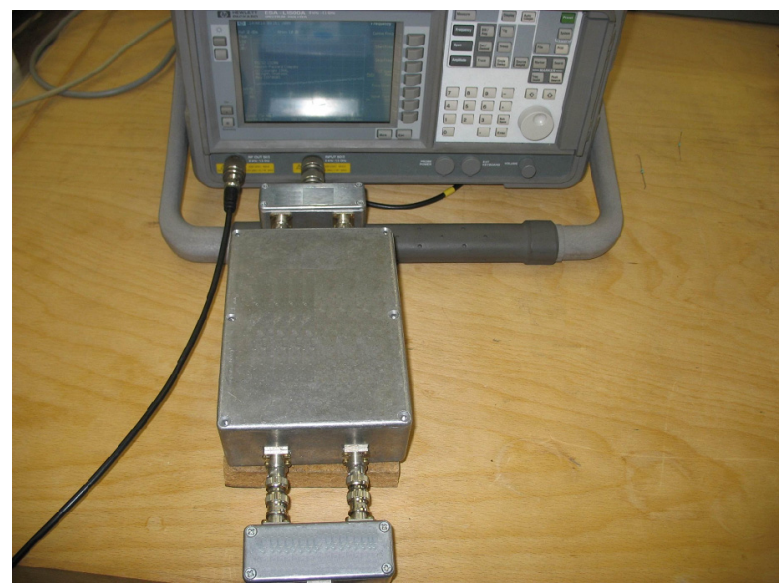

Fig. 14. EMI filter characterization

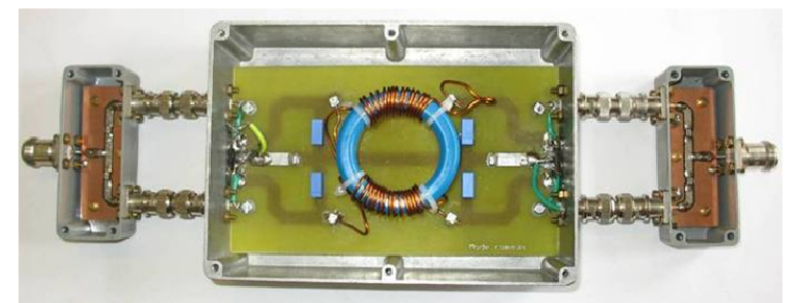

Fig. 15. Experimental EMI filter characterization for $\mathrm{CM}$ 


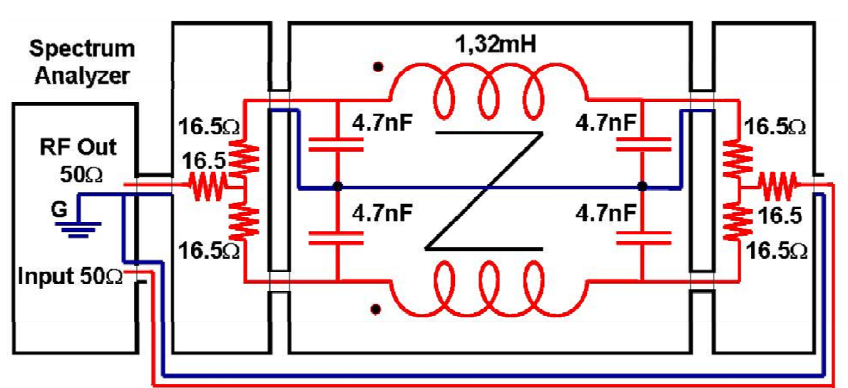

(a): Common Mode filter

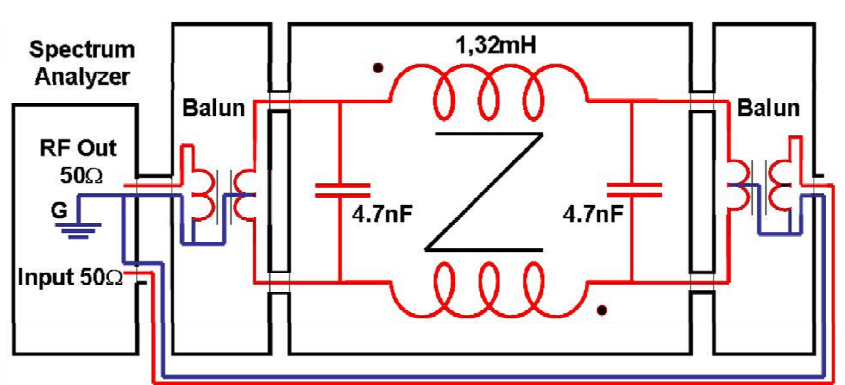

(b): Differential Mode filter

Fig. 16. Measurement method of the CM and DM filters attenuations

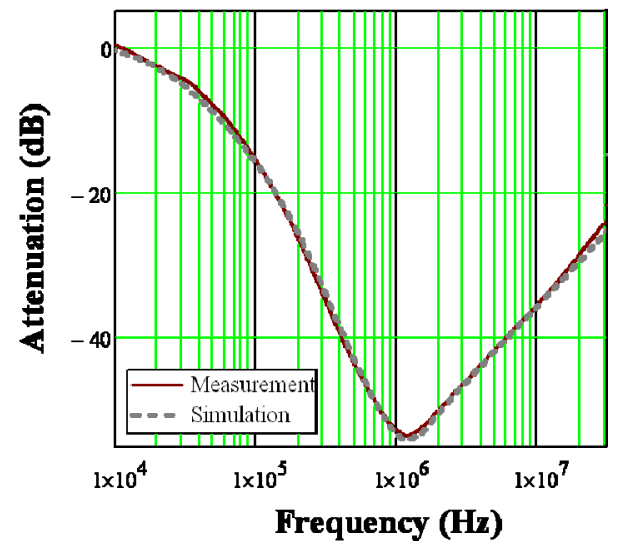

Fig. 17. Common mode filter response. Tracking generator power level (output) is equal to $3 \mathrm{dBm}$

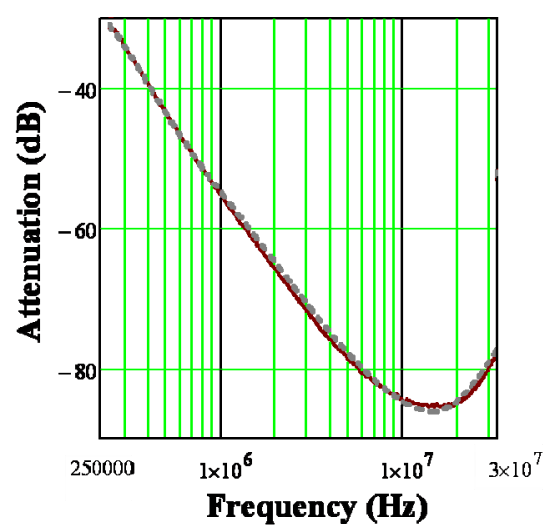

Fig. 18. Differential mode filter response. Tracking generator power level (output) is equal to $0 \mathrm{dBm}$

\section{CONCLUSION}

In this paper, an electrical equivalent circuit of coupled inductors used in EMI filters is detailed. The symmetric model proposed takes into account of the high frequency phenomena which appear when the frequency increase. The identification method of the model parameters using impedance measurements in different configurations tests has been proposed. The obtained model has been tested and validated for common mode inductors. The proposed model of the coupled inductors is used in the simulation of EMI filter. The obtained results show very good agreement between a simulation results and experimental 
data up to $30 \mathrm{MHz}$. The next work consists to optimise the EMI filters (Weight, dimensions ...) by simulation using the proposed

EMI filter model associated to the high frequency models of the power converters and Line Impedance Stabilisation Network.

\section{REFERENCES}

[1] S. Wang, Y. Y. Maillet, F. Wang. D. Boroyevich, R. Burgos, "Investigation of Hybrid EMI Filters for Common-Mode EMI Suppression in a Motor Drive System," IEEE Transactions on Power Electronics, Vol.25, № 4, April 2010, pp.1034-1045.

[2] H. Akagi, H. Hasegawa, T. Doumoto, "Design and performance of passive EMI Filter For Use with A Voltage-Source PWM Inverter Having Sinusoidal Output Voltage And Zero Common-Mode Voltage", IEEE Transactions on Power Electronics, Vol.19, N 4, July 2004, pp.1069-1076.

[3] W. Xiaofeng, X. Dehong, Z. Yanjun, C. Yi, O. Yasuhiro, M. Kazuaki, "Integrated EMI Filter Design with Flexible PCB Structure", IEEE Power Electronics Society, PESC08, Rhodes, Greece, June 15-19 2008, CD proceeding, pp. 1613-1617.

[4] N. Idir, R. Bausière, J. J. Franchaud, "Active gate voltage control of turn-on di/dt and turn-off dv/dt in insulated gate transistors", IEEE Transactions on Power Electronics, Vol. 21-4, july 2006, pp.849-855.

[5] A. Videt, P. Le Moigne, N. Idir, P. Baudesson, X. Cimetiere, "A New Carrier-Based PWM Providing Common-Mode-Current Reduction and DC-Bus Balancing for Three-Level Inverters", IEEE Transactions on Industrial Electronics, Vol.54, N 6, december 2007.

[6] H. Chen, Z. Qian, Z. Zeng and C. Wolf, "Modeling of parasitic inductive couplings in a Pi-shaped common mode EMI filters", IEEE Trans. on Electromagnetic Compatibility, Vol.50, N1, February 2008.

[7] R. Chen, J. D. Van Wyk,S. Wang, W. G. Odendaal, "Improving the Characteristics of Integrated EMI Filters by Embedded Conductive Layers", IEEE Transactions on Power Electronics, Vol. 20, No. 3, May 2005.

[8] X. Wu, D. Xu, Z. Wen, Y. Okuma, K. Mino, "Design, Modeling, and Improvement of Integrated EMI Filter With Flexible Multilayer Foils," IEEE Transactions on Power Electronics, Vol.26, N.5, May 2011, pp.1344-1354.

[9] F. Leferink, H. Bergsma, B. Ferreira, W. Van Etten, "High Performance EMI Filter for Frequency Converters", EMC Europe 2004, Eindhoven.

[10] Shuo Wang, F.C. Lee, D.Y. Chen and W.G. Odendaal, "Effects of Parasitic Parameters on the Performance of EMI Filters", IEEE Trans. on Power Electronics, Vol. 19, May. 2004, pp. $869-877$.

[11] S. Wang, F. C. Lee, W. G. Odendaal, " Characterization and Parasitic Extraction of EMI Filters Using Scattering Parameters", IEEE Transactions on Power Electronics, Vol. 20, N², March 2005.

[12] http://www.epcos.com/web/generator/Web/Sections/ProductCatalog/Ferrites/

[13] X. Margueron, J-P. Keradec, "Design of Equivalent Circuits and Characterization Strategy for n-Input Coupled Inductors", IEEE Transaction on Industry Applications, Vol.43, №1, Jan./Feb. 2007, pp.14-22.

[14] X. Margueron, J-P. Keradec, "Identifying the Magnetic Part of the Equivalent Circuit of n-Winding Transformer", IEEE Transactions on Instrumentation and Measurement, Vol.56, ํㅜ 1, February 2007, pp.146-152.

[15] Agilent 4294A Precision Impedance Analyzer-Operation Manual, Agilent Technologies.

[16] S.Wang, F. Lee,W. Odendaal, and J. vanWyk, "Improvement of EMI filter performance with parasitic coupling cancellation," IEEE Transactions on Power Electronics., vol. 20, no. 5, pp. 1221-1228, Sep. 2005.

[17] G. Grandi, I.Montanari, and U. Reggiani, "Effects of power converter parasitic components on conducted EMI," in Proc. Int. Symp. Electromagn. Compat. (EMC Zurich), 1997, pp. 499-504. 
[18] H. Zhu, A. Hefner, Jr., and J. Lai, "Characterization of power electronics system interconnect parasitics using time domain reflectometry," IEEE Trans. Power Electron., Vol. 14, № 4, pp. 622-628, Jul. 1999.

[19] T. C. Neugebauer and D. J. Perreault, "Parasitic capacitance cancellation in filter inductors," IEEE Transactions on Power Electronics, vol. 21, no. 1, pp. 282-288, Jan. 2006.

[21] M. C. Caponet, F. Profumo, A. Tenconi, A., "EMI filters design for power electronics," Power Electronics Specialists Conference, 2002. pesc 02. 2002 IEEE 33rd Annual, Vol. 4, 23-27 June 2002, pp. 2027 - 2032.

[22] Y. Maillet, L. Rixin, W. Shuo, W. Fei, R. Burgos, D. Boroyevich, "High-Density EMI Filter Design for DC-Fed Motor Drives," Power Electronics, IEEE Transactions on Power Electronics, Vol.25, N.5, May 2010, pp.1163-1172.

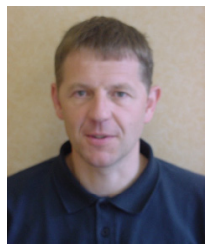

Jean-Luc Kotny received the Ph.D. degree from the University of Lille 1, France, in 1984. He is currently an Assistant Professor with the University of Lille 1 . His main research interests include power electronics and electromagnetic compatibility.

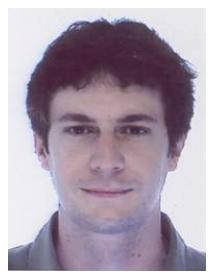

Xavier Margueron (M’09) was born in Chambery, France, in 1980. He received the Diploma in electrical engineering from the Ecole Nationale Supérieure d'Ingénieurs Electriciens de Grenoble, Grenoble, France, in 2003, and the Doctorat de Génie Electrique from the Université Joseph Fourier, Grenoble, in 2006. Its principal fields of research related to passive components and HF modelling. Since September 2007, he has been an associate professor at the Ecole Centrale de Lille, France, where he carries out research in the L2EP laboratory. His research interests are HF power electronics and passive component modelling and optimization.

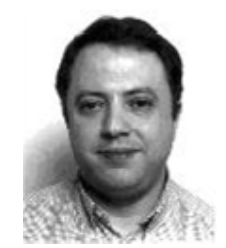

Nadir Idir (M'07) received the Ph.D. degree from the University of Lille, France, in 1993. He is currently a Professor with the Laboratory of Electrical Engineering and Power Electronics (L2EP) of the University of Lille. His main research interests include power electronics and electromagnetic compatibility. 